\title{
"FRAY LAZO: EL ANTICLERICALISMO RADICAL ANTE EL DEBATE CONSTITUYENTE DE LA SEGUNDA REPÚBLICA ESPAÑOLA (1931)"
}

\author{
POR \\ Manuel Álvarez Tardo \\ Universidad Complutense
}

\begin{abstract}
ResUMen
Durante los primeros meses de la Segunda República española, el postulado secularizador fue fundamental para la definición política de un amplio sector republicano y socialista. Dentro de los partidarios de una política de secularización activa hubo un grupo proclive y especialmente sensible a los dictados del anticlericalismo radical; apoyado por un cierto número de parlamentarios y por la actitud anticlerical de la prensa republicana, tuvo una manifestación especialmente significativa, un semanario exclusivamente anticlerical: Fray Lazo (1931). El análisis y contextualización de los contenidos y formas de esta publicación a la luz del debate constitucional del verano y otoño de 1931 revela la importancia que esa postura anticlerical radicalizada tuvo para el equilibrio político y la definición jurídica del nuevo sistema político.
\end{abstract}

\begin{abstract}
During the first year of the Spanish Second Republic, an important part of the republican and labour movement adopted the idea of securalization as an strategic element in their position on the political debate. There were a special group among them who was specially sensible and receptive to the radical anticlericalism; they worked together with a parliamentarian group and the very important support of the republican press; moreover there was an exclusive anticlerical journal: Fray Lazo (1931). This article presents an analysis in context of that joumal and special view of their postulates in the constitutional debate (1931); through this view it will be posible to show that that radical anticlericalism played an important role in order to obtain a particular political agreement and legal definition of the new political system.
\end{abstract}

Aficiones y devociones en el antiguo régimen Hispania Sacra 50 (1998) 
Este trabajo aborda anticlericalismo español contemporáneo en una de sus facetas más clarividentes, la manifestación mediante la prensa de la crítica política contra la Iglesia católica. Y lo hace en un contexto especialmente relevante, el del comienzo de las políticas secularizadoras de los años treinta; momento en que el republicanismo, en connivencia con el socialismo, elaboraba el marco constitucional del nuevo régimen republicano inaugurado el 14 de abril de 1931.

Precisamente porque aborda el anticlericalismo, dos puntualizaciones son necesarias en esta introducción. En primer lugar, el anticlericalismo español contemporáneo puede definirse de múltiples maneras, pero todas ellas acabarán desembocando en una serie de rasgos comunes. Por no entrar en polémicas conceptuales muchas veces estériles, puntualizo aquí que este trabajo aborda el anticlericalismo refiriéndose a una actitud ideológica que, dentro de su particular visión de la realidad, considera a la Iglesia católica -en tanto que institución- como el principal representante de un antiguo régimen superado, como el enemigo fundamental de la modernidad; en definitiva, a efectos políticos, para ser anticlerical no hacía falta quemar iglesias - aunque éso llamara y llame mucho la atención, incluso sabiendo que quienes las quemaban eran a veces unos chiquillos que probablemente no sabían ni leer las arengas anticlericales- como teorizar, polemizar y elaborar una visión crítica global de la Iglesia católica y sus miembros. En ese sentido, estoy de acuerdo con Remond cuando señala que el anticlericalismo es mucho más que una ideología meramente negativa; aunque creo que ese valor positivo, esa construcción de un ser anticlerical, no siempre fue el resultado de una contestación, no siempre nació de un peligro inminente, sino que formó parte de una elaboración política, de un conjunto de ideas que aportaban una cosmovisión de la realidad en un periodo en el que la movilización política creciente y el aumento de la competencia entre élites rivales favoreció la oportunidad de ese discurso anticlerical ${ }^{1}$. Que mejor medio para conocer ese discurso que el análisis de la prensa exclusivamente anticlerical en un año como 1931, momento en el que las esperanzas secularizadoras del anticlericalismo español tenían todo su ánimo depositado en las Cortes Constituyentes elegidas el 28 de junio.

En segundo lugar, ser y pensar como un anticlerical implic 6 en casi todos los casos una posición militante a favor de la secularización; esto es, para el universo anticlerical, secularizar dejó de ser una corriente inherente a la modernidad para convertirse en un acto que, o se impulsaba o no se producía. Militar en la fe secularizadora era la mejor muestra de la rabia contenida contra el clero y todo lo que éste representaba. Por eso es necesario diferenciar - a efectos de

1 Véase R. REMOND, L'anticlericalisme en France. De 1815 a nos jours, Bruselas, 1985, especialmente pp. 171-218.

Aficiones y devociones en el antiguo régimen

Hispania Sacra 50 (1998) 
este análisis y en un plano más teórico que real-- entre la secularización de lo político y la secularización de lo social. La primera es una secularización básicamente institucional -las asociaciones humanas, incluido el Estado se emancipan de la tutela política y cultural de la iglesia católica-; por tanto, se trata de un acto más ligado a la actividad legisladora y reguladora del Estado. La segunda, sin embargo, tiene mucho más que ver con la pérdida de relevancia de lo religioso en las relaciones humanas que se producen en el ámbito de la sociedad civil; y, como tal, es dudoso que pueda ser el resultado exclusivo de la actividad estatal $^{2}$. Quienes pretendían secularizar en los años treinta olvidaron muchas veces que, justificadas o no las críticas contra la intolerancia y la intransigencia de la Iglesia, el Estado no podía ser constitucional y liberal si se imponía así mismo - al confundirse con un Estado-partido al servicio de intereses particulares- la tarea de secularizar las conciencias. La ansiada libertad de conciencia que tanto esfuerzo había costado instaurar descansaba sobre un discurso ambiguo en el que ser liberal y ser anticlerical era, en cierto casos, incompatible.

La secularización política, inspirada e informada por los principios liberales, había sido el resultado de una necesidad imperiosa de emancipar al Estado del peso político y económico de la Iglesia. Se había llevado a cabo la desamortización de las propiedades eclesiásticas -comenzada en España a finales del siglo XVIII y concluida a mediados del siguiente-y se había asegurado el control regalista de la actividad interna de la Iglesia. Fue, precisamente entonces, cuando una nueva generación de católicos empezó a comprender que la batalla del futuro no era tanto por la recuperación de las propiedades como por evitar algo que empezaba a ser cada vez más preocupante para su razón de ser; esto es, la secularización progresiva de las conciencias. A pesar de hechos como el Concordato de 1851 o la confesionalidad del Estado, los católicos no disfrutaban ya de una posición hegemónica indiscutible. Tanto ellos como los no católicos supieron apreciar el fondo de esa especie de batalla por el control de las conciencias. Desgraciadamente, pocos respetaron escrupulosamente una competencia leal, sin apropiaciones del Estado para fines propios; la negativa católica a reconocer la libertad de conciencia fue tan intolerable como la actitud anticlerical dispuesta a convertir la libertad de conciencia en negación de toda presencia pública de la religión ${ }^{3}$.

2 Una sintesis reciente del debate sobre la secularización es R. WALLIS y S. BRUCE, "Secularization: trends, data and theory", en Research in the Social Study of Religion, vol. 3, pp. 1-31 (1991). Véase tambien J. CaSANOVA, Public Religion in the Modern World. Chicago, 1993, espec. pp. 1-37; y K. DOBBELAERE, "Secularization: a multidimensional concept", en Current Sociology, vol. 29, n ${ }^{\circ} 3$, pp. 1-153 (1981).

3 Véase W.J. Callahan, Iglesia, poder y sociedad en España, 1750-1874. Madrid, 1989; J.S. PÉrez GARZÓN, "Curas y liberales en la revolución burguesa", en R. CRUZ (ed.), El anticlericalismo. Ayer, $\mathrm{n}^{\mathrm{a}}$ 27, 1997, pp. 67-101; J. MERCADER RIBA, "Los origenes del anticlericalismo español", en 
En la España contemporánea, el discurso anticlerical entró en su fase decisiva con el cambio de siglo. Entre 1898 y 1909 se fundieron en un mismo lenguaje la batalla política contra el clericalismo y los postulados laicos que reclamaban un mayor peso del Estado en la educación en detrimento de la posición de las órdenes religiosas. En ese periodo, el anticlericalismo pasó a ser un recurso esencial de la movilización y diferenciación ideológica de los republicanos, herederos declarados de la tradición del radicalismo demócrata del siglo anterior. Con esto, lo que hasta entonces había sido un debate intelectual y de círculos restringidos, en cierta manera diferenciado del proceso de secularización estatal, se fue popularizando y adentrando en la conciencia de sectores sociales a los que el odio al clero no les era demasiado extraño ${ }^{4}$.

Ese nuevo anticlericalismo combativo recogió y perfeccionó la herencia del siglo anterior: las violencias populares contra el clero; el debate entre razón y fe que había sido cultivado con intensidad creciente después del Syllabus y que acabaría por trasladarse a un enfrentamiento doctrinal entre liberalismo y catolicismo; y el enfrentamiento político entre el Estado liberal español y la Iglesia católica, en un proceso de emancipación del primero que le permitiera poner las bases de un nuevo marco económico, constitucional y burocrático. En fin, todo eso permitió que en los primeros años del nuevo siglo el anticlericalismo viviera un periodo de robustecimiento y consolidación de su discurso, llegando a convertirse en un apoyo ideológico de considerable valor estratégico y una importante rentabilidad popular.

La crítica al maridaje político entre la Iglesia católica y el dictador Miguel Primo de Rivera reforzó la confusión ideológica entre republicanismo y anticlericalismo. La Segunda República nació con una promesa implícita, consolidar en el ámbito de lo social la revolución política del 14 de abril; ahí es donde se encontró la raiz del problema religioso, en la necesidad de emprender una "revolución religiosa" que eliminara toda influencia clerical, porque "el clericalismo es enemigo de toda democracia, y la forma republicana es forma polí-

\footnotetext{
Hispania, $n^{\circ} 33,1973$, pp. 101-123; M. REVUELTA GONZÁLEZ, Política religiosa de los liberales en el siglo XIX. Trienio Constitucional. Madrid, 1973, espec. pp. 54-120; M. REVUFETA GONZÁLEZ, "El proceso de secularización en España y las reacciones eclesiásticas", en P. ALVAREZ LAZARO, Librepensamiento y secularización en la Europa Contemporánea. Madrid, 1996, espec. pp. 321-372; y J. CARO BAROIA, Introducción a una historia contemporánea del anticlericalismo español, Madrid, 1980.

4 Sobre la elaboración y radicalización del discurso anticlerical en la primera década de este siglo pueden verse: J. ALVAREZ JUNCO, El emperador del paralelo. Lerroux y la demagogia populista, especialmente pp. 397-417; J. ROMERo MAURA, La rosa de fuego: el obrerismo barcelonés de 1889 a 1909. Madrid, 1989., espec. pp. 162-177; J. ConNelly UllMAN, La Semana Trúgica. Barcelona, 1972; y J. CUEVA MERINO, Clericales y anticlericales. El conflicto entre confesional y seculariz. en Cantabria (1875-1923), Santander, 1994.
}

Aficiones y devociones en el antiguo régimen Hispania Sacra 50 (1998) 
tica eminentemente democrática"s. En ese ambiente, la prensa se convirtió en el eje básico del discurso anticlerical hasta que en el verano de 1931 se inició el debate parlamentario de la cuestión religiosa. Junto a los grandes diarios republicanos del momento, no faltó el sustancioso apoyo de un semanario exclusivamente dedicado a la crítica anticlerical más extrema; un semanario que, inspirado y declarado heredero de El Motín, dio cabida a aquellos más dispuestos a combatir con la pluma al enemigo central de la República, al ogro clerical.

Fue Fray Lazo, Semanario anticlerical cortesmente desvergonzado. Su vida fue corta pero intensa y correspondió al momento crucial en la definición constitucional del problema religioso. Su primer número salió a la calle el 13 de agosto de 1931, pocos días antes de que diera comienzo en las Cortes el debate a la totalidad del proyecto constitucional; y su último número, el 21, lo hizo el 30 de diciembre de aquel mismo año, algunas semanas después de que se aprobara la Constitución de la Segunda República ${ }^{6}$. Al margen del grado de su presencia y difusión pública, Fray Lazo condensó gran parte de los elementos de la tradición anticlerical en un momento en que el discurso anticlerical más radical tuvo una relevancia extraordinaria en el transcurrir del debate constitucional, en la resolución concreta del enfoque que habría de darse a la llamada cuestión religiosa.

\section{FRAY LAZO: ANTICLERICALISMO Y DEBATE CONSTITUCIONAL.}

Al igual que amplios sectores de la tradición anticlerical hispánica, Fray Lazo no se caracterizó por su irreligiosidad. Todavía en los años treinta, uno de los elementos básicos del anticlericalismo republicano consistía en olvidar la discusión, la confrontación entre razón y fe; Fray Lazo solía ignorar un debate puramente religioso que no era asequible a todos sus lectores, que no tenía el gancho de la crítica anticlerical clásica y no formaba parte de la razón de ser de un anticlericalismo político que seguía considerando la fe como un asunto

5 El LibERAl, 18 de abril de 1931, p. 3. Éste artículo condensó algunos de los elementos que la crítica anticlerical expuso durante aquellos días en la prensa nacional más relevante. Destaca la conexión irrenunciable entre República, cambio social revolucionario y actitudes anticlericales.

6 Cada número solía tener entre veinte y treinta páginas cuyo denominador común era un anticlericalismo tan disperso como amplio, que iba desde la representación satírica del escenario político hasta el tono conibativo y la crítica mordaz, irónica y agria, pasando por todo tipo de historias anticlericales, recuperación de antiguos textos de El Motín, viñetas cómicas, radiografias políticas, cuentos celestiales, cartas pastorales, crónicas parlamentarias... Sus colaboradores más frecuentes fueron Augusto Vivero, Antonio de Lezama, Arturo Mori, José Balbotín, Luis de Tapia, P. Ramiro Casas, Salvador Valverde, E. Paul Almara, Eduardo Barriobero y Herrán; aunque sólo por una ocasión y muy fuera de tono también tuvo cabida la pluma de Miguel Unamuno. 
interior del individuo en nada comparable con las manifestaciones clericales. El anticlericalismo continuaba siendo una cuestión de principios y formas políticas, culturales y sociales. Incluso en los casos en que Fray Lazo atacaba sin piedad los fundamentos del derecho de enseñanza de los religiosos no se llegaba a afrontar una crítica antireligiosa; la educación del fraile era perniciosa porque corrompía y viciaba la persona e inculcaba valores antidemocráticos y antirepublicanos, pero esto no solía derivarse de la fe, sino de la instrumentalización que de ella hacía el clericalismo con fines políticos, sociales y económicos. El anticlericalismo seguía siendo, pues, una cuestión relativa a lo público ${ }^{7}$.

Para ser anticlerical había que comulgar con un credo, con un catecismo de recetas mágicas cuyo primer punto reflejaba una definición del enemigo, del figurín clerical $^{8}$. Si había que seducir al público y conseguir que se sintiera identificado en la línea de trabajo del semanario, nada mejor que esclarecer ese objetivo clerical, aquello que unía a los verdaderos republicanos en la lucha que finalmente desterraría al clericalismo de la península. La actualidad hacía los honores, la máxima preocupación de los republicanos era combatir a los sectores de la derecha católica. El anticlericalismo, mucho más que una mera actitud defensiva o reformista, aportaba una crítica coherente y una cosmovisión de la realidad con implicaciones en todos los ámbitos de la vida. Por eso, el anticlericalismo radical que caracterizó a gran parte de los republicanos era un vehículo, un arma política para enfrentarse a un sector del país, la derecha católica, el mayor enemigo de la República. El anticlericalismo adquiría así toda su dimensión táctica; era el símbolo de una identidad de fe republicana desde el que plasmar los principios de la revolución popular. Los clericales representaban un orden que no solo era contrario a ese nuevo régimen sino que intentaría a toda costa destruirlo; eran aquellos que tras la "discrección aparente, tras la sumisión hipócrita al poder constituido", tras esa "argumentación jesuítica propia de una edad de piedra decentita" escondían una defensa de un orden muy particular de explotación, dominio y servilismo ${ }^{9}$. El catolicismo en manos de los clericales era el arma del capitalista, del especulador antipatriota que quería arruinar la España republicana, era el instrumento que historica-

7 Este elemento resulta a todas luces importante porque, como se verá más adelante, el discurso radical del anticlericalismo republicano, aun siendo expresión de una lucha perteneciente al ámbito de lo público, herencia de un primer anticlericalismo nacido de las filas liberales- no tuvo reparos en invadir y perseguir ciertos comportamientos y prácticas individuales estrictamente privados. La confusión de lo público y lo privado --mejor dicho, la subordinación del segundo al primero- era uno de los elementos que en la práctica determinaban gran parte del discurso ideológico anticlerical, un discurso que olvidaba que el liberalismo hacía ya tiempo que había diferenciado con claridad ambas esferas, estableciendo los límites de lo público como garantía del derecho y la libertad del individuo.

8 Fray Lazo, 13 de agosto de 1931, n. 1, p. 5.

9 Fray Lazo, ibíd. 
mente se había demostrado como el más poderoso valedor del control social y la defensa de una política que preservaba el orden de signo reaccionario y capitalista que ahogaba todo espíritu de libertad.

El anticlericalismo empezaba, pues, con el tono combativo que a su juicio requería el debate constitucional. En las Cortes Constituyentes, los defensores a ultranza de la Iglesia católica apenas llegaban a un diez por ciento; por el contrario, dominaban aquellos que era propicios, en un grado u otro, a la implantación de medidas constitucionales que resumiesen los objetivos históricos de la secularización. ¿Qué preocupaba a Fray Lazo y a ciertos ámbitos del republicanismo?, ¿por qué esa insistencia en definir al clerical típico que actuaría en las Cortes para salvar los restos de un orden llamado a desaparecer? Básicamente dos razones: primero, porque sin un enemigo no hay guerra que ganar y, segundo, porque el espíritu de ese anticlericalismo radical iba más allá de la mera reforma secularizadora, pretendía y aspiraba a una Constitución que negase la más mínima posibilidad de supervivencia a la Iglesia. Ante una Iglesia perdida que iba a capitular a regañadientes, era mejor estar a la defensiva, había que privarla hasta del más mínimo tanque, la Iglesia no tenía derecho a negociaciones concordatarias ni estatutos particulares; la revolución republicana así lo había querido ${ }^{10}$.

Sin embargo, los primeros artículos de Fray Lazo no atacaban al clerical conservador y reaccionario, al párroco combativo o a la representación eclesiástica que negociaba con el Gobiemo. A medida que pasó el tiempo, pudo verse que la crítica tenía un objetivo más claro y menos incierto, esto es, evitar la línea de moderación que determinados sectores podían imponer a la Cámara. Como había ocurrido desde el 14 de abril, la lucha real no era contra los católicos - aunque estos eran la base justificativa del argumento-, sino contra los mismo republicanos que se negaban a reconocer el verdadero valor de la revolución popular. El peligro estaba, pues, dentro del régimen republicano, entre los constituyentes. En el lenguaje anticlerical más radical había mucho más de táctica política que de reivindicación histórica, era un combate a muerte por un tipo de República'1.

En aquel mes de agosto de 1931 las condiciones en que debía desarrollarse el anticlericalismo habían variado sustancialmente respecto de la primavera. Apenas faltaban quince días para que diera comienzo el debate a la totalidad del proyecto constitucional. Un primer anteproyecto constitucional había sido ya rechazado; se sabía que el Gobiemo no pensaba defender en bloque ningu-

10 Fray Lazo, 13 de agosto de 1931 , n. 1, p. 2.

II "Porque nuestros políticos, y entre ellos incluyo a muchos republicanos, antes que políticos, que demócratas, que hombres de ley y que hombres de ciencia, han sido católicos, lo que vale tanto como decir hombres que renunciaron del derecho a discernir y al deber de opinar", en Fray Lazo, Ibíd. 
na postura concreta sobre el texto constitucional, es más, el mismo Gobiemo que decía ésto mantenía por vías oficiosas conversaciones con representantes de la Iglesia católica para llegar a algún tipo de compromiso sobre la posición de la Iglesia en la carta magna ${ }^{12}$. Sin una posición conservadora y católica de peso en la Cámara, no parecía que fuera a darse un debate a muerte con clericales inexistentes que permitiese enarbolar la bandera de la necesidad histórica de un anticlericalismo radical.

El máximo obstáculo de los anticlericales estaba dentro del bando republicano, en la ambigüedad y la indecisión. Aunque se vistieran los argumentos con el ropaje tradicional del lenguaje anticlerical, en los primeros meses el enfrentamiento y la lucha política se desarrollaron dentro del republicanismo. Por esa razón, desde el principio, Fray Lazo no dudó en iniciar el debate contra los ministros que representaban o postulaban la moderación y la negociación con la Iglesia. Aunque el tono del semanario se mantuvo siempre en la línea de apoyo a los radical-socialistas - los más anticlericales de las Cortes-, también es cierto que no solía arremeter contra la Acción Republicana de Azaña, al que se elogiaba por su labor al frente del Ministerio de Guerra, y del que se esperaba - como estaba entonces haciendo gran parte de la prensa republicana- el primer disparo que habría de iniciar el definitivo ataque al clericalismo ${ }^{13}$. El objetivo de Fray Lazo era, por el momento, mucho más que los ataques y la ironía despiadada contra Maura y Alcalá Zamora; había que concentrarse en la traición del socialista Fernando de los Ríos y el radicalsocialista Álvaro de Albornoz. Al primero por su labor moderada al frente del ministerio de Justicia, y al segundo por su actitud ambigua, pasiva y de cierto alejamiento del radicalismo que caracterizaba a sus compañeros de la Cáma-

12 Las relaciones entre el Gobieno y la Iglesia durante el verano de $1931 \mathrm{cn}$ : M. BATLLORI Y V.M. ARBELOA, Iglesia y Estado durante la II Republica. Arxiu Vidal i Barraquer; varios documentos en Tomo I, vol I, pp. 195-273 (en adelante AVB); también pueden seguirse por M. AZAN̄A, Memorias, Barcelona, 1977, diferentes anotaciones de los meses de agosto y septiembre; N. ALCALÁ ZAMORA, Mis Memorias, Barcelona, 1977, pp. 183-203; D. MARTINEZ BARRIO, Memorias, Barcelona, 1983, pp. 70-83. En cuanto a bibliografia secundaria véase: V.M. ARBELOA, La semana trágica de la Iglesia en España (octubre de 1931), Barcelona, 1976; F. de MEER, La cuestión religiosa en las Cortes de la II República, Pamplona, 1975; y el análisis de S. JULIA, Manuel Azaña. Una biografía política. Del Ateneo al Palacio Nacional, Madrid, 1990, especialmente pp. 121-137.

13 "Lo peor es que todavía este ejército nutrido, y bien nutrido, está en pie de guerra. No ha babido un Azaña que lo reduzca. Y con el tendremos que combatir los soldados de la ley y de la civilidad para libertar al Estado de su opresión y de su saqueo". En Fray Lazo, Ibid. El aumento de ta popularidad de Azaña y las repetidas manifestaciones de la prensa republicana sobre su figura política en S. JuLia, op. cit. pp. 111-121; véanse también los elogios a Azaña en EL LIBERAL (Madrid), 2 de agosto de 1931 .

Aficiones y devociones en el antiguo régimen Hispania Sacra 50 (1998) 
$\mathrm{ra}^{14}$. Fray Lazo empezaba así a desentrañar los hilos del equilibrio político que iba a caracterizar el debate parlamentario de la Constitución en lo referente a la familia y la religión. Se hacía, pues, una llamada de atención a los ministros citados, a la vez que se mantenía como en una uma, intacto pero predispuesto, a Azaña. La crítica más furiosa se reservaba para aquellos que poco podían pintar en la República, Maura y Alcalá Zamora. Se sabía que, a partir del proyecto constitucional, el que éste se atemperara o se radicalizara iba a depender de la actitud de los jefes parlamentarios respecto de sus minorías. Había que recordar a los ministros radical-socialistas y socialistas, pues parecían haberlo olvidado, de donde procedían: "Muy señores míos, ni ustedes son anticlericales, como se hacían llamar antes de obtener el Poder, ni, por lo que se ve, en España los hay. De lo contrario, ¿cómo no hubiesen ustedes decretado la expulsión de los frailes, y si ustedes olvidaban sus compromisos de la oposición, cómo el pueblo, a fuerza de manifestaciones, no había de recordárselos e imponerles su cumplimiento?"'15

Fray Lazo se arrogaba así, desde los primeros números, la representación del verdadero anticlericalismo que la revolución republicana había dictado. Por encima de toda la panoplia del discurso anticlerical, el objetivo básico de la crítica era construir un tipo de República concreto y diferenciado, un texto constitucional que consagrase los principios de la revolución - si España era católica, dejaría de serlo por necesidad democrática, si no lo era, se confirmaría el camino para ratificarlo-. En la labor que Fray Lazo se asignó a sí mismo hubo dos vertientes: primero, desarrollar y cultivar los aspectos clásicos del lenguaje anticlerical ante la opinión pública republicana y con el objetivo de reforzar el principio de la necesidad histórica de la revolución secularizadora; y, segundo, participar del debate parlamentario de la Constitución en la línea de un anticlericalismo integrador y movilizador al servicio de la causa revolucionaria. En este sentido, el anticlericalismo era mucho más que la denuncia del poder clerical, pasaba a ser el eje vertebrador de una nueva política arropada por la terminología ideológica del revolucionarismo pasional y demagógico. Por eso, cuando comenzó el debate a la totalidad del proyecto constitucional, el semanario no dudó ni un solo instante en reclamar para sí el verdadero ser de la República.

No se trataba sólo de defender la reforma religiosa, la manifestación anticlerical era la señal de alerta para una República que estaba en crisis -consideraba Fray Lazo apenas cinco meses después de proclamada-. Hasta ese momento

14 Desde los primeros días del gobierno provisional en abril de 1931, Fernando de los Ríos había sido manifestado ante la prensa la cautela y prevención con que actuaría el gabinete ante la cuestión religiosa. Veanse sus declaraciones en EL LIBERAL (Madrid) de 16, 17 y 19 de abril de 1931.

15 Fray Lazo, 13 de agosto de 1931, n. 1, p. 18. 
no había habido República, ni Gobierno, ni acomodo al ambiente nacional; España reclamaba un Gobierno de izquierdas, homogéneo, intérprete del sentir republicano, "que recogiese todo el espíritu de la revolución."16 A España, sin embargo, se le imponía un "gabinete híbrido, apocado, borroso, en el que predominaba un incomprensible aliento conservador, contradictorio con lo que [habían sido] axiomas de la contienda contra la Monarquía y con todo lo que [eran] aspiraciones del pueblo" republicano. Las clases directoras se habían separado del pueblo revolucionario que había traido la República; la retórica y el oficialismo habían disfrazado un espíritu conservador, habían dado por resultado unas "Cortes de terdera, lamentables"; pero el pueblo revolucionario salvaría a su República que no era la "del corazón de Jesús, encarceladora de republicanos mientras [cambiaba] sonrisas versallescas con el nuncio de Roma."17

El resultado era, claro está, la crítica contra los conservadores Alcalá Zamora y Miguel Maura ${ }^{18}$; la crítica también contra el socialista Fernando de los Ríos, pero en un tono más moderado y pedagógico para el segundo, porque en su caso sólo se trataba de advertir, de instruir, de recordar al ministro de Justicia que era "demasiado condescendiente", que todos esperaban de él "medidas más izquierdistas." 19 El anticlericalismo de Fray Lazo superaba así su propia dimensión particular, con un discurso ideológico más amplio que no sólo denunciaba al clericalismo sino que trataba de recordar a los republicanos, al Gobierno y a las Cortes cuál era el alma revolucionaria de la República; de ahí la denuncia de la docilidad y el gregarismo de los diputados ${ }^{20}$.

Aquel tono combativo se mantuvo durante toda la vida de Fray Lazo y, especialmente, durante el debate constitucional. A los ojos del anticlericalismo radical el artículo 24 del proyecto constitucional era poco más que una cesión a la Iglesia, una amenaza a la libertad de pensamiento que ponía en crisis la República ${ }^{21}$. La verdad republicana, decía Fray Lazo, era una y sólo una; frente a ella no había más que un abismo que conducía a una complacencia y

\footnotetext{
16 Fray Lazo, 27 de agosto de 1931, n. 3, p. 2.

17 Todo lo anterior desde la última cita, en Fray Lazo, Ibíd.

18 Fray Lazo, 13 de agosto de 1931, n. 1, p. 18; Fray Lazo, 20 de agosto de 1931, n. 2, p. S.

19 Fray Lazo, 27 de agosto de 1931 , n. 3, p. 25.

20 "A unas Cortes revolucionarias a las que asuste la palabra Convención o les inspire temor tener que aplicar las leyes que fabrican, no se les puede confiar gran cosa. Además, ¡los extremismos políticos tienen tan pobres y desmedrados voceros!"; en Fray Lazo, 27 de agosto de 1931, n. 3, p. 26.

21 El artículo 24 del proyecto (Título III, Cap. 1) decía así: "Todas las confesiones religiosas podrán ser consideradas como asociaciones sometidas a las leyes generales del país. El Estado no podrá, en ningún caso, sostener, favorecer ni auxiliar economicamente a las Iglesias, asociaciones e instituciones religiosas. El Estado disolverá todas las Órdenes religiosas y nacionalizara sus bienes." En Apéndice $4^{\circ}$ al $n^{\circ} 22$ (18-8-1931) del Diario de Sesiones de las Cortes Constituyentes (en adelante citado como DSSC). La crítica anticlerical en Fray Lazo, 27 de agosto de 1931, n. 3, p. 2.
} 
moderantismo propios del orden conservador. La Constitución no habría de poner sólo las bases de la reforma religiosa, sino que debía consagrar una secularización implantada por la vía revolucionaria, había de articular la República "amada y venerada. Los pactos y transacciones con monárquicos y clericales abominables" eran innecesarios. El pueblo había impuesto "el régimen y no lo hizo para que más tarde se le traicionara" Era ya la "hora histórica de la articulación de la República", había que "republicanizar la República, en culto a la Verdad, a la Libertad y a la Justicia, nuestra Trinidad sacrosanta."22

Fray Lazo asumía así todo el peso del discurso anticlerical anterior. Si revolución y secularización habían sido términos confundidos en gran parte de los postulados republicanos y socialistas durante la primavera de 1931, ahora que se hacía necesario reforzarlos, el semanario se presentaba como el nuevo párroco de la aldea parlamentaria, como el confesor de los vicios transaccionales del republicanismo desviado de la verdadera fe revolucionaria. La radicalidad de su lenguaje era muy oportuna; tras las elecciones de junio, republicanos de izquierda y socialistas se habían hecho dueños de las Cortes que iban a aprobar la Constitución, pero en medio estaban todavía los conservadores y los lerruxistas. El republicanismo más anticlerical era consciente de que sin una labor de proselitismo no sería posible encauzar la discusión constitucional en tonos revolucionarios. Las Cortes habían aprobado la acción política del Gobierno provisional anterior a las elecciones y Maura y Alcalá Zamora seguían en sus puestos de poder. Además, ni los radical-socialistas Domingo y Albomoz ni Azaña se habían opuesto de manera decidida a las negociaciones que encabezaban Fernando de los Ríos y el Presidente del Gobierno Alcalá Zamora con la nunciatura y los representantes del Arzobispo de Tarragona, Vidal i Barraquer, en Madrid. Se estaba fraguando un principio de acuerdo entre la Iglesia y el Gobiemo. Sin embargo, como muy bien conocían los republicanos y el mismo Fray Lazo, existía una Cámara plagada de anticlericales dispuestos a votar, no ya el artículo 24 del proyecto, sino uno mucho peor para los católicos. Nadie sabía por el momento - esto es, el mes de septiembrecómo se comportarían los ministros y jefes de minoría con sus respectivos grupos parlamentarios, una vez llegada la hora de discutir y votar el artículo. Pero sí era patente que se iba a producir un choque considerable y que ni los socialistas, ni los radical-socialistas, ni el grupo de Azaña iban a ceder fácilmente a la vía transaccional del Gobierno.

Por eso mismo, Fray Lazo, en mayor medida que parte de la prensa republicana y socialista, decidió cultivar a fondo un anticlericalismo radicalizado hasta el extremo que permitiera crear la sensación de que existía una opinión

22 Todo lo anterior desde la última cita en Carta Pastoral de Fray Lazo a todos los republicanos, en Fray Lazo, 16 de septiembre de 1931, n. 6, p. 2. 
pública republicana indispuesta con esa línea de moderación gubernamental y nada partidaria de aceptar la traición de sus representantes en la Cámara. La clave de los meses de septiembre y octubre iba a estar en la actitud que finalmente asumieran los ministros republicanos y socialistas. Antes, pues, de que llegara la discusión del artículo 24, había que presionar y jugar el papel que correspondía a un semanario de esas características.

Durante el verano de aquel año se había mantenido en vigor un debate de gran transcendencia y que había sido levantado a raiz del primer proyecto constitucional presentado por la Comsión Jurídica que nombró el Gobierno en junio. Nadie tenía una idea clara de cual debiera ser el status de la Iglesia católica tras la separación del Estado que debía recoger la Constitución. Desde determinados sectores del republicanismo conservador se señaló que sólo unas negociaciones entre el Gobierno y la Iglesia podían solucionar esa duda; para unos había que llegar a un nuevo Concordato, mientras que para otros grupos republicanos -esa fue la postura de Alcalá Zamora como vía, según él, menos mala- - con un modus vivendi era suficiente por el momento, porque sin ser un Concordato, permitía resolver las cuestiones básicas y evitar mayores polémicas. Por lo que sabemos, el Gobierno provisional optó por negociar oficiosamente con la iglesia los asuntos más delicados, como eran el presupuesto de culto y clero y la situación de los centros docentes de las órdenes religiosas. Claro está que a los ojos del republicanismo más anticlerical, así como de la prensa que había protagonizado antes de las elecciones la construcción de un discurso tan anticlerical como revolucionario, cualquier vía de negociación con la Iglesia católica era una traición y un riesgo inadmisible ${ }^{23}$. Esa era la posición del republicanismo de Fray Lazo; conocedor de las divergencias dentro del Gobierno respecto de las relaciones con la Iglesia, no dudó ni un solo instante en denunciar en varios artículos toda vía de negociación y transacción con los católicos. La crítica del semanario contra un nuevo Concordato se articulaba en tomo a dos ejes: por un lado, cualquier acuerdo con la Iglesia no se produciría entre partes iguales ya que ni aquella era un Estado soberano ni podía exigir al Gobiemo español ninguna concesión; el Estado no debía ceder a la sumisión del poder civil ante los antojos de Roma, más aun cuando los clericales usarian aquello como un recurso para salvar parte de la nave que se hundía; la República no tenía que ceder a ningún chantaje, ni el pueblo lo había querido así ni ese era el medio para atacar la estructura social y política del clericalismo. De otro lado, cualquier cesión o pacto con la Iglesia era tanto como reconocer su poder externo

23 El discurso anticlerical en cierta prensa antes de las elecciones de junio de 1931 puede seguirse, entre otras fechas, en El SOCIALISTA, 14, 20 y 25 de junio de 1931; El LIBERAL (Madrid), 13, 16, 18 y 19 de junio de 1931; EL HERALDo de MADRID, 16 de junio de 1931.

Aficiones y devociones en el antiguo régimen Hispania Sacra 50 (1998) 
y permitirles conservar los tanques para que siguieran con su lucha. Para Fray Lazo, la relación Iglesia-Estado no existía ni debía existir ${ }^{24}$.

En el fondo, negar toda vía de relaciones con Roma era como negar su existencia; era una declaración de principios sobre la que debía asentarse la República. Para el anticlericalismo que representaba el semanario no había mas que una solución al problema clerical y era la de aniquilar, desterrar de la sociedad y de la política toda influencia clerical. El problema era que aquella consideración obligaba a los católicos a radicalizar su defensa, a la vez que deslegitimaba los esfuerzos de moderación de parte de la jerarquía eclesiástica. Como sabían algunos miembros del gobierno, esa radicalización anticlerical en el texto constitucional se volvería contra la propia práctica política republicana, a modo de un boomerang descontrolado; por eso, entre otras razones, buscaron una vía de negociación que atemperase ese posible resultado. En el fondo, se estaban enfrentando dos posturas divergentes. La primera negaba todo principio democrático de respeto y libertad de conciencia -aunque esa fuera su bandera--, porque es evidente que no podía construirse un régimen constitucional y democrático que amparase en su Constitución la, persecución y anulación de un cuerpo público de creencias y prácticas sociales, por mucho que el fin justificase los medios. La segunda, en principio la de Alcalá Zamora y Fernando de los Ríos, respaldada tímidamente -más por un silencio positivo que por una afirmación de lealtad gubernamental- por el resto de los ministros republicanos de la Alianza Republicana, consideraba el riesgo de aislar a los católicos en una República que se decía democrática y deseaba evitar la politización del debate religioso mediante unos acuerdos con la Iglesia que permitiesen implantar ciertas reformas secularizadoras sin polémicas estériles que llegasen hasta la opinión pública y sin que eso fueta bandera de combate en la discusión constitucional.

Fray Lazo sabía que una labor constante de denuncia y ostigamiento permitiría radicalizar las posturas de los núcleos parlamentarios socialista y radical-socialista, haciendo posible una indisciplina frente a sus jefes políticos en el momento de la discusión de los artículos sobre religión. En la medida en que esos líderes eran presos de un discurso próximo al del semanario, cultivado apenas unos meses atrás en la campaña electoral, cualquier labor de crítica

24 Véanse diferentes artículos en: Fray Lazo, 13 de agosto de 1931, n, 1, p. 2; Fray Lazo, 9 de septiembre de 1931, n. 5, p. 8; En Fray Lazo, 9 de septiembre de 1931, n. 5, p. 19, se señalaba: "Es sabido que las Iglesias, en abriéndoles el portillo, hacen, cuanto les conviene, de lo divino, humano, de lo humano, divino; sus muchos affos de historia y actuación blondinesca lo atestiguan firmemente; no hay, pues, mejor que dar resueltamente un "tajo a la maroma". Y se acabaron las piruetas. Porque el Concordato es para las Iglesias eso: una maroma, fácilmente convertible, por otra parte, en disciplina para azotar al pueblo." 
anticlerical que conjugase revolución republicana y acción anticlerical, a la vez que denunciase la moderación gubernamental, podía poner contra las cuerdas la ambiguedad del hacer político de aquellos.

El 27 de agosto comenzó en el Congreso el debate a la totalidad del proyecto constitucional presentado por el Presidente de la comisión parlamentaria que lo había elaborado, Luis Jiménez de Asua ${ }^{25}$. El debate duró hasta el 8 de septiembre y en el intervinieron numerosos ponentes, representantes algunos de los grupos parlamentarios, otros en nombre propio y otros como independientes. No por casualidad, los temas más comentados fueron el problema de la tierra, la estructura territorial del Estado y la cuestión religiosa. Sobre 21 intervenciones, al menos 14 contenían referencias al problema religioso, y no precisamente de un modo sucinto y generalista como hubiera correspondido a un debate a la totalidad. Se comentaron y detallaron algunos de los temas más polémicos de las relaciones Iglesia-Estado, la situación de la Iglesia en el nuevo Estado republicano, el presupuesto de culto y clero, los ańlisis en clave histórica sobre el maridaje de Iglesia y Monarquía... Concluido el debate, un aspecto sobresalía por encima de cualquier otro: casi todos los grupos parlamentarios carecían de una opinión propia, homogénea y detallada, sobre el contenido que debiera reflejar la Constitución en lo referente al problema religioso. Había multitud de puntualizaciones y particularidades, el debate parecía más bien el de una asamblea de historiadores reunidos para juzgar la evolución de la Iglesia católica en la política española de los últimos cinco siglos. La tónica general consistía en aceptar que la Constitución debía suponer una obra conservadora de la República -como había dicho Jiménez de Asua en la presentación del proyecto a la Cámara-, es decir, un cuerpo jurídico que consagrase los logros de la revolución republicana; para esto era requisito esencial que se reflejasen en la carta magna los principios de la secularización política y social. Aunque no estaba muy claro hasta donde debía llegarse, casi nadie desde el campo republicano se atrevía por aquel entonces a negar explícitamente -aunque la ambiguedad de algunos así lo dejaba entrever- el artículo 24 tal y como el proyecto lo recogía. El futuro debate artículo por artículo se presentaba cargado de tensión e incertidumbre.

Mientras, entre finales de agosto y principios de septiembre, continuaban las conversaciones entre el Gobiemo y la Iglesia. Un día después de concluido el debate a la totalidad, se reunían en Madrid el Presidente del Gobiemo, Alcalá Zamora, y el entonces máximo representante del episcopado español, el Arzobispo de Tarragona, Vidal i Barraquer ${ }^{26}$. El objetivo del primero era conseguir que Roma retirara al Cardenal Pedro Segura de su primacía toledana;

25 El debate a la totalidad del proyecto constitucional en DSSC, pp. 642-800.

26 Véase AVB, 14 de septiembre de 1931, doc. n 134, p. 303, Tomo I, vol I. 
gracias a eso, el Gobierno afrontaría con más fuerza moral un atemperamiento de la discusión religiosa en las Cortes. Mientras se conseguía o no, el 17 de septiembre - en el momento de discutirse en la Cámara el artículo 3 del proyecto, referente a la confesionalidad del Estado-, Jiménez de Asua propuso el aplazamiento del debate para que pudiera ser tratado conjuntamente con los otros artículos sobre religión y familia. La proposición fue aprobada y Alcalá Zamora logró de este modo un respiro a la espera de las decisiones de Roma ${ }^{27}$.

Hasta principios de octubre, una vez iniciado el debate a la totalidad de los artículos sobre la religión y la familia, el Ministro de Justicia y el Presidente del Gobierno no anunció la remoción del Cardenal Primado de Toledo, Pedro Segura. El estado de la cuestión se estaba, pues, complicando día a día; por un lado, había que interpretar la decisión de Roma como una concesión al Gobierno al hilo de las conversaciones y acuerdos informales que se habían producido -el Gobierno tenía una cierta obligación moral de moderar el artículo 24 y conseguir excluir ciertas cuestiones religiosas de la Constitución-; de otro lado, en el Parlamento había crecido mucho la tensión, el ambiente relajado y distendido de agosto empezaba a desaparecer ${ }^{28}$. Así las cosas, el 8 de octubre empezo el debate de los artículos sobre religión y familia; hubo, hasta el mismo día 14 en que se procedió a la votación final, una completa incertidumbre sobre el resultado final.

El 7 de octubre, Fray Lazo había publicado su número nueve. La crítica principal iba dedicada a los que pedían una Constitución moderada en la que no se excluyese a los católicos. "Los clericales que infestaban los partidos monárquicos infesta[aban entonces] los republicanos"; la renovación que pedía el pueblo se podía "quedar en una simple transfusión"29. El Gobiemo, con esos falsos neorepublicanos y prohombres que desde el Pacto de San Sebastián habían hecho y deshecho sin contar con el pueblo, estaba vendiendo la República a ese "clericalismo de gorro frigio" cuya primera victoria había sido "conseguir suave, mansamente, que se demorase (...) el análisis y votación de los artículos del proyecto constitucional que tocan los asuntos religiosos". Y ante eso, decía Fray Lazo, "la prensa republicana puede hacer mucho"; tiene el

\footnotetext{
27 Véase DSSC, p. 989.

${ }^{28}$ Se habían producido diversos incidentes que demuestran la importancia de la mecánica parlamentaria: primero, el incidente entre el diputado radical-socialista Botella Asensi y Alcalá Zamora que había desembocado en un conato de dimisión del Presidente; y, segundo, la discusión del derecho de voto de la mujer que había enfrentado a radical-socialistas y socialistas -con la amenaza de los primeros, una vez perdieron la votación y se concedió el derecho de voto a la mujer, de tomar represalias de cara a la votación de la cuestión religiosa-. Véase V.M. ARBELOA, La semana trágica,.., pp. 51 y ss.

29 "Transfusión tanto más odiosa ya que impone a los españoles seguir padeciendo lo mismo de antes, tan execrado, sin otra diferencia que una simple mudanza exterior de apelativos"; en Fray Lazo, 7 de octubre de 1931, n. 9, p. 2.
} 
deber ineludible de informar a los "electores republicanos de que constituyentes votan contra la separación del Estado y la Iglesia; quienes pugnan contra la legítima ilusión nacional de que desaparezca el injusto presupuesto ecelesiástico; quienes votan en pro de que continúe soportando España los miles y miles de frailes y monjas volcados sobre nosotros." 30

Ese anticlericalismo escondía una opción de República, y sólo una. Su exclusividad chocaba, no ya con los católicos, sino con aquellos que desde el campo republicano pugnaban por defender un marco constitucional plural. Así como las posiciones de la derecha republicana nicetista y la de los radicalsocialistas eran bien conocidas, la opción final del voto socialista, radical e incluso azañista era una incógnita. La presión sobre el debate parlamentario se dirigió, pues, primero contra los nicetistas y, segundo, contra aquellos falsos republicanos que iban a traicionar al pueblo. Pero, claro está que no podían ponerse - al menos por el momento- ni frente a los socialistas ni frente a Azaña; luego hubieron de explicarse cargando contra la derecha, insinuando la posible traición de los republicanos y socialistas si no optaban por la República anticlerical y revolucionaria. No se podía dejar que Fray Niceto y Fray Miguelito convenciesen con sus sermones al resto de los republicanos de que Dios creo España para que fuese paraiso de los PP y MM de todos los colores y calibres que viven a costa del sudor ajeno. Ojo a lo que se pastelee, jcorreligionarios!. ¡Luz y taquígrafo!. Y sobre todo, espiritu republicano. Que la República no vino para que fuera lo que anunció Fray Niceto ${ }^{31}$.

En la Cámara, el equilibrio era tenso, cada vez aumentaban más las interrupciones y los incidentes; ningún ministro ni ningún grupo de la Alianza Republicana o de los socialistas se atrevía a salir en defensa de un marco constitucional amplio que no implatara per se la persecución religiosa. Por eso se optaba por aplacar las iras anticlericales con lenguajes ambiguos y proposiciones que escondían un falso anticlericalismo, en comparación al de los amigos de Fray Lazo. Los comentaristas y articulistas del semanario conocían aquello, y no sólo azuzaban a favor de medidas anticlericales duras sino que desmenuzaban y aclaraban las maniobras de moderación en el interior de la Cámara. Ni al Papa Negro -Alcalá Zamora-ni al habilidoso Don Alejandro - Lerroux - se les iba a consentir "apuntarse un tanto ante la galería." 32

\footnotetext{
30 Fray Lazo, Ibid.

31 Fray Lazo, 7 de octubre de 1931, n. 9, p. 2

32 En tono satírico comentaba sobre los frailes: "¿Quemarles? La atmósfera sería irrespirable. ¿Encerrarles? Faltarían cárceles. ¿expulsarles? Volverían en seguida. ¿Dejarles? ¡Sí, hornbre, sí! Pero con una condición que se convirtieran en custodia de la República, velando por su seguridad, por su tranquilidad y por su prosperidad, y haciéndoles responsables directos de todos los transtomos que clla sufriese"; en Fray Lazo, 7 de octubre dede 1931, n. 9, p. 6. Sobre discurso tenso y dificil de Fernando de los Ríos en la presentación del debate el acho de octubre, comentaba irónicamente Fray
} 
Para Fray Lazo, las Cortes habían iniciado el "ataque religioso contra las normas anticlericales del proyecto constitucional" y pronto se vería, si antes no se remediaba, como se "traicionaban las historias y programas, se anulaban los partidos y se hacía burla de lo que se prometió a las gentes, no ya en tiempos de la Monarquía, pero aún en la última propaganda electoral." Y no iba muy descaminado el autor, había que recordar a los socialistas y republicanos de centro-izquierda el anticlericalismo cultivado con dureza durante los meses de mayo y junio. Enmiendas para moderar el artículo 24, como la de Acción Republicana, brindaban desataban las iras anticlericales. Fray Lazo era consciente de las maniobras que dentro de la Cámara intentaban moderar el artículo 24, aquellos eran los "auxiliares del clericalismo que actúan desde el campo republicano"33.

No faltó tampoco una crítica algo más cercano a la explicación de los contenidos anticlericales clásicos. La República, recordaba el semanario, había nacido para realizar una "cruzada laica". Fray Lazo, a pesar de su anticlericalismo radical extremo cuando se trataba del debate constitucional, sabía que del texto constitucional saldría, al menos, un auténtico empuje secularizador que, aunque no se manifestara con el "radicalismo que exigen los tiempos", sí iba a lograr "aterrorizar a esas superviviencias de las edades troglodíticas a quienes se les va el dominio espiritual"34. La República, si no expulsaba a las órdenes, al menos emanciparía las conciencias; ese era un requisito esencial de la supervivencia del régimen, era una cuestión de salud pública ${ }^{35}$.

Y pasó el 14 de octubre y se aprobó el artículo 26 --antiguo 24 - con una redacción un tanto diferente a la señalada por el semanario y los núcleos duros del anticlericalismo en la Cámara; iqué moderación la de la enmienda azañista así comparada!"36. Tras el "pastel" - así llamaba Fray Lazo al artículo definiti-

Lazo: "El discurso con que Fernando de los Ríos ha iniciado el debate religioso, ha producido tan excelente efecto en el Vaticano, que el ministro socialista será nombrado inmediatamente camarero secreto de capa y espada de nuestro Santísino Padre Pio XI "; en Fray Lazo, 14 de octubre dede 1931, n. 10 , p. 2 .

33 Todas las citas de éste páarrafo último en Fray Lazo, Ibíd.

34 Fray Lazo, 14 de octubre de 1931, n. 10, p. 15.

35 Así resumía el semanario su propuesta secularizadora, la cruzada laica que debía seguir a la Constitución: había que hacer una "campaña enérgica e incansable por ciudades y campos, pidiendo la liberación espiritual de los españoles, fa separación de Ia Iglesia y el Estado, el sometimiento absoluto de todas las asociaciones, religiosas o no, a las leyes; la incautación de los bienes indebidamente detentados, la expulsión de las Órdenes religiosas que constituyan un peligro para la patria, la secularización de los cementerios, el matrimonio civil como único y supremo contrato de la sociedad conyugal, el divorcio, la enseñanza integralmente laica, será lo que salve a nuestro país y lo ponga en el rango de las Repúblicas de verdad"; en Fray Lazo, ibíd.

36 El artículo 26 definitivo decia así: "Todas las asociaciones religiosas serán consideradas como Asociaciones sometidas a una ley especial. El Estado, las regiones, las provincias y los Municipios, no mantendrán, favorecerán, ni auxiliarán económicacmente a las lglesias, Asociaciones e Institucio- 
vo- - la situación era peor que con el Concordato; aquella redacción había sido un verdadero regalo a la Iglesia, se había "sustituido una cosa de presente por una monserga de futuro". Azaña, decía el semanario, había conseguido la jefatura del Gobierno gracias a una "formula pastel" que abría el futuro a toda suerte de "cubileteos" 37 . Fray Lazo, atento al transcurrir parlamentario, había captado a su modo lo que políticamente representaba la solución dada al tema religioso. Era, al fin y al cabo, algo más que una escrupulosa libertad de conciencia -recogía en cierta manera gran parte de las demandas anticlericales, lo cual no dejaba de alegrarles - pero mucho menos que un ataque fulminante y directo contra la Iglesia católica. Solo los radical-socialistas y los nicetistas habían estado en su puesto - consideraba el semanario-; a pesar de los socialistas y de otros grupos republicanos, el influjo del anticlericalismo de los jabalíes había satisfecho, aunque parcialmente, a Fray Lazo.

A partir de ese momento, al igual que los diputados de la derecha católica aunque por motivos radicalmente opuestos, Fray Lazo inició su propia campaña de revisión; se trataba de impedir que la Constitución se quedara en simples palabras, de ahí que la campaña consistiera en la presión sobre el gobierno para que afrontase la reforma religiosa pendiente. ${ }^{38}$ Ahora bien, lo que pasó en los meses siguientes fue parte de un futuro al que semanario no sobrevivió.

\section{EL CONTENIDO DE LA CRÍTICA ANTICLERICAL. Temas básicos.}

Por último, tras el análisis de la posición y expresión de Fray Lazo durante el debate constitucional, hay que añadir algunas notas sobre los contenidos y temas básicos que sirvieron al semanario para reforzar el siempre confuso discurso anticlerical. Todos ellos fueron una repetición de los postulados clásicos de la batalla secularizadora y no se diferenciaron en exceso - a no ser por su radicalismo y sus formas satíricas - de los de la campaña anticlerical que la

nes religiosas. Una ley especial especial regulará la total extinción, en un plazo máximo de dos años, del presupuesto đel Clero. Quedan disueltas aquellas Órdenes religiosas que estatutariamente impongan, además de los tres votos canónigos, otra especial de obediencia a autoridad distinta de la legítima del estado. Sus bienes serán nacionalizados y afectados a fines benéficos y docentes. Las demás Órdenes religiosas se someterán a una ley especial votada por estas Cortes Constituyentes y ajustada a las siguientes bases (...)."

37 Fray Lazo, 21 de octubre de 1931, n. 11, p. 2.

38 Para la campaña de revisión y la consiguiente labor de difusión de los postulados anticlericales y de los deseos expresos de convertir en realidad lo que eran sólo promesas constitucionales véanse: Fray Lazo, 21 de octubre de 1931, n. 11, p. 25; 14 de noviembre de 1931, n. 13, p. 5 y 6; 25 de noviembre de 1931, n. 16, p. 21 ; y 2 de diciembre de 1931 , n. 17, p. 2.

Aficiones y devociones en el antiguo régimen Hispania Sacra 50 (1998) 
prensa republicana y socialista sostuvo antes de las elecciones para Cortes Constituyentes del mes de junio.

No se resistió Fray Lazo a la tentación de empezar su andadura pública sin hacer algún comentario sobre los sucesos incendiarios de mayo de aquel año que le habían precedido en el tiempo. La quema de conventos era un símbolo que no podía desperdiciarse; un poema de Luis de Tapia recogía el tema con un sátira mordaz y elocuente hasta el extremo, señal de cual iba a ser la línea predilecta del semanario, la de ridiculizar hasta el extremo las actitudes del falso republicanismo y consagrar su lucha diaria a un objetivo pedagógico y aleccionador con el que enseñar al pueblo republicano las verdaderas fauces del lobo clerical ${ }^{39}$.

Para la mayoría del espectro republicano la Iglesia había representado de siempre aquel poder fáctico atento a sus exclusivos intereses políticos y económicos, dispuesta a aprovechar su influenicia moral y cultural sobre la sociedad - especialmente sobre los jóvenes y sobre las mujeres- para moldear y controlar Ias conciencias. Por eso Fray Lazo insistió una y otra vez en los aspectos políticos claves del anticlericalismo: la Iglesia era un poder supranacional sin escrúpulos y con gran capacidad de movilización e implantación, dispuesta a luchar por el control político del pueblo que la asegurase el mantenimiento de su status social y económico. La Iglesia era, pues, el enemigo central de aquellos que querían republicanizar el país; Ia revolución republicana que iba a hacer justicia en el campo, en las fábricas y en las escuelas inquietaba a una Iglesia detentadora de una posición de poder que corría peligro.

Frente a la unión de Trono y Altar, la República - para los anticlericales, un Estado fuerte dispuesto a implantar la secularización social y políticarepresentaba un solo poder, una sola opción que no era compatible con esa Iglesia podrida de actitudes clericales clásicas. Era una lucha política y social; la crítica antireligiosa estaba casi ausente de las páginas del semanario; la fe y el clericalismo eran dos cosas bien distintas.

En la lucha secularizadora, cualquier oportunidad era buena para hacer frente al enemigo, para asociar el mayor número de problemas con un clericalismo que era mucho más que el clero, era el soporte de un orden en el que la fe era el instrumento de dominación y servilismo que permitía la explotación económica capitalista. Al clásico patriotismo regenerador del discurso republicano se unía ahora un patriotismo económico reforzado por la creciente imagen de Estado extranjero que tenía la Iglesia a los ojos del pueblo ${ }^{40}$.

39 Fray Lazo, 20 de agosto de 1931, n. 2, p. 5

40 La asociación de anticlericalismo y patriotismo ecónomico en Fray Lazo, 13 de agosto de 1931, n. 1, p. 5. 
Frente al orden clerical había que construir el orden republicano, o uno u otro. Y ese orden nuevo no era, pues, compatible con la mera separación de la Iglesia y el Estado; porque separar era tanto como dejar libre a la Iglesia para que cultivara su propio orden. La radicalización del anticlericalismo consistía en considerar, en concluir en todos los casos en una fe estatista tan magnífica como etérea que confiaba en el Estado como revulsivo histórico para acabar con la Iglesia y el orden que ésta representaba. Una fe que veía el proceso de secularización como si de un golpe de fortuna revolucionaria se tratara; la República sólo estaría a salvo si se traducía en la realización práctica de esa fe, si el Estado se convertía en el instrumento con el que barrer la influencia política, social y cultural del clericalismo.

Para cultivar esta fe secularizadora no eran bien recibidos los debates serenos ni los análisis históricos rigurosos, sino los tópicos de siempre que el pueblo republicano alcanzaba a comprender y sufrir: el fraile y la monjita eran los auténticos responsables de la pobreza, los saqueadores del pobre trabajador, quienes se llevaban el pan de nuestros hijos ${ }^{41}$; las asociaciones femeninas de carácter religioso eran el vivo ejemplo de la acción de los padres espirituales sobre la mujer ${ }^{42}$; y, por supuesto, los jesuitas, los eternos explotadores y acaparadores de la riqueza nacional, eran el centro por excelencia de la diana anticlerical, el más vivo ejemplo de la impureza moral y cristiana del clericalismo; el jesuita, frente al fraile sencillo y pobre, era el detentador del poder, el explotador del pueblo y del clero bajo, "el dueño de la enseñanza y de las conciencias de la gente rica", el máximo peligro para la República, aquel que "domina, pues, en España por su influencia, riqueza y negocios, no obstante de hallarse en el Gobierno los ministros que se dicen anticlericales." 43

Junto a todo eso, Fray Lazo solía recurrir a la tradición anticlerical heradada, no sólo para reforzar así su crítica, sino también para apuntalar esos tintes milenaristas que siempre acompañaban el discurso anticlerical. La literatura de antiguos anticlericales como Joaquín Dicenta ${ }^{44}$ conformaba una especie de Biblia del anticlericalismo, eran los textos sagrados que debían guiar la batalla secularizadora, aquellios que mejor podían conducir al pueblo republicano en su envite definitivo por el cual recuperar la verdadera fe crisitana perdida. Porque el lenguaje anticlerical no sólo no era antireligioso sino que estaba

\footnotetext{
41 Fray Lazo, 13 de agosto de 1931, n. 1, p. 18.

42 La relación clericalismo-control de las conciencias-voto femenino era uno de los temas predilectos del semanario, que se expresaba así en una de tantas ocasiones: "El confesionario primero y la urna después serían un verdadero encanto ciudadano, una coyunda digna de ser enelatecida por la Acción Nacional"; en Fray Lazo, 13 de agosto de 1931, n. 1, p. 5.

43 Fray Lazo, 13 de agosto de 1931, n. 1, p. 28.

44 Cuento Celestial de Joaquín Dicenta, en Fray Lazo, 20 de agosto de 1931, n. 2, p. 10.
} 
cargado de ética cristiana; la denuncia de la falsa moral de los clericales era un objetivo prioritario que enaltecía y purificaba el enfrentamiento histórico que, por fin, había llegado a su momento cumbre, al momento en el que, tras barrer al enemigo que tenía secuestrada la fe, se recuperaría la pureza y la justicia crisitana olvidadas. El cuento celestial de Dicenta no era otra cosa que una parodia del juicio final en la que se enfrentaban metafóricamente los actores de la lucha terrenal por la secularización; la Virgen representaba la pureza y la inocencia femenina pervertida y desviada por la influencia de un temible monje capuchino de "cuerpo enjunto, flaco a tal punto que sobre la tela del hábito se marcaban los huesos; su demacrado rostro, encuadrado por una larga y no muy limpia barba gris; sus ojos hundidos, sus profundas arrugas y sus ojeras violáceas." 45 Frente a la implacable actitud vengativa del fraile - no por casualidad era un regular y no un simple párroco--, la Virgen conseguía evitar el purgatorio para los pecadores, la Virgen-Madre emocionada lograba salvarlos del infatigable capuchino. La lucha contra las órdenes tenía, pues, un final feliz y justo; el noble pueblo atrapado en sus garras conseguía despertar la pureza de la justicia y el perdón cristiano, desenmascaraba la falsa moral del clericalismo regular que no sólo no trabajaba por la fe sino que lo hacía por el enriquecimiento personal y el mantenimiento del privilegio adquirido, llegando a subordinar a ese poder los valores que les hacían ser tal.

A los ojos anticlericales, la denuncia ética reforzaba el conjunto de la crítica contra el fraile, convertida así en fraylazo, en "clérigo entregado por entero a la vida material: cardenales con tres automóviles y cuatro queridas; canónigos de coro y siesta; curas de misa y caza; sin otras inquietudes que las del semental. He aquí nuestro clero." 46 Y ese clero pervertido y explotador, continuaba el semanario, no era, al fin y al cabo, más que el resultado de un proceso histórico que había iniciado la "fragua troglodítica de la Inquisicion". Precisamente porque no era algo natural sino fruto de una perversión histórica, la pureza del clero podía ser recuperada; en eso consistía la cruzada laica y anticlerical, la República era el momento determinado por el curso histórico para acabar con el falso catolicismo, para iniciar el camino de la modernidad; sólo con la expulsión de los regulares se "conseguiría la paz social y el progreso humano de España." ${ }^{" 47}$ La vida monacal era, por tanto, la negación radical de

\footnotetext{
45 Fray Lazo, ibid.

46 Continuaba asi: "Es muy raro encontrar algún clérigo español que tenga alguna idea, por vaga que sea, sobre los fundamentos filos6ficos del catolicismo"; en Fray Lazo, 27 de agosto de 1931, n. 3, p. 5.

47 El fin del clericalismo era siempre la señal de salida de la carrera modemizadora, del progreso y la riqueza futura del país. Véase para la cita Fray $L a z o$, ibíd.
} 
los valores cristanos, la reacción del miedo y la cobardía, el principio de todo aquello que dificultaba el progreso nacional ${ }^{48}$.

Ese clero regular también representaba aquello que más odiaban los republicanos, el orden monárquico bajo el cual había crecido el poder de las órdenes y su influencia peniciosa sobre la educación de "ocho generaciones" 49. Los frailes, que durante la Restauración habían sido la bandera católica de la recuperación eclesiástica en el terreno educativo y social, eran ahora la antítesis perfecta del progreso republicano. El fraile que deprimía, castraba, embrutecía y deformaba a los que educaba - según los tópicos del anticlericalismo- no ślo era un símbolo clerical sino también el adalid de la identificación histórica de la Monarquía con el reaccionarismo absolutista y el monarquismo. Era el más absoluto "fraude, la exageración y la mentira", el padre de las "falsedades que han dificultado la marcha del cristianismo." 50

En resumen, si se centraban las críticas sobre el clero regular no era por capricho oportunista, sino por necesidades del discurso. El clero regular representaba en las conciencias individuales el ejemplo de una vida secreta y desconocida, embidiada y odiada. Era el centro de los refranes y de la sátira anticlerical más popular, el enemigo visible al que incendiar las propiedades, el personaje adecuado para focalizar todas las iras en una misma dirección. Además, para los anticlericales, desde un punto de vista político, las Órdenes --especialmente los jesuitas ${ }^{51}$ — habían protagonizado históricamente la unión de Trono y Altar, la defensa intransigente de la intolerancia religiosa, el control de los centros de educación superior y, cómo no, la ligazón de capitalismo y catolicismo. El grito de ;Viva la República! no podía quedar solo, sino con este otro: ;Abajo los frailes ${ }^{52}$

\footnotetext{
48 El fraile era el origen "đe los milagros falsos, de las falsas tradiciones, supercherías, creencias exageradas; (...) de las sectas y herejías conocidas; (...) del odio a la carne ..."; en Fray Lazo, 27 de agosto de 1931, ibíd., p. 7.

49 Fray Lazo, ibíd.

50 Fray Lazo, ibíd.

51 Los jesuitas, al igual que en la tradición anticlerical de la Restauración, fueron el objetivo preferido de las páginas de Fray Lazo. No por casualidad, en septiembre de 1931 -después de iniciado el debate constitucional y antes de la discusión sobre la disolución de las Órdenes- se produjo una oleada de artículos dedicados a ellos en los que se relataban las historias de la riqueza y las villanías jesuíticas desde el Renacimiento hasta la Restauración canovista. Véanse: Fray Lazo, 16 de septiembre de 1931 , n. 6, p. 9.; 23 de septiembre de 1931, n. 7, p. 18; y 30 de septiembre de 1931, n. 8, p. 18 y 19.

52 Fray Lazo, ibíd.
}

Aficiones y devociones en el antiguo régimen

Hispania Sacra 50 (1998) 


\section{CONCLUSIONES}

Con anterioridad a la Segunda República, la impronta del anticlericalismo en el republicanismo español había superado su carácter oportunista para convertirse en un cuerpo ideológico cada vez más radicalizado al servicio de la construcción de una cultura política común. Una cultura que, obsesionada por implantar la secularización social por la vía del decreto gubernativo, subordinó la conjugación de liberalismo, democracia y progreso a un golpe de efecto revolucionario con forma de República. De este modo, la estructura constitucional, ese marco amplio que regula el juego político dando cabida al mayor número de opciones ideológicas posibles, se convirtió en un instrumento de consagración revolucionaria al servicio de la transformación del Estado y la sociedad.

Esa herencia común se convirtió en el mejor soporte del republicanismo más radicalmente demócrata, dispuesto a cultivar en cuanto se proclamara la República un peligroso lenguaje revolucionario cuya manifestación más concreta y cercana era la destrucción del figurín clerical. Aquel anticlericalismo intransigente y obsesivo era minoritario dentro del republicanismo pero supo condicionar el transcurrir de la definición constitucional del nuevo régimen, como meses atrás.había ocurrido en el debate electoral y en el progresivo aislamiento de una opción republicana conservadora. Es más, la izquierda republicana y los socialistas no tuvieron inconveniente en explotar un legado común muy rentable, el de un anticlericalismo usado como vía de diferenciación política y movilización electoral, actitud que tuvo consecuencias importantes de cara al proceso constitucional. En ese momento, aunque Azaña consiguió atemperar el ataque contra las órdenes religiosas tras su famoso discurso del 14 de octubre de 1931, el definitivo aislamiento del republicanismo conservador y católico no pudo evitarse y, al final, el fantasma de una crisis grave de gobierno que pusiera en entredicho la solidez del bloque parlamentario que sostenía al gobierno sólo se eludió a costa del ataque expreso contra los jesuitas y de una redacción constitucional que dificultaba aún más la integración de los católicos en el régimen.

Fray Lazo fue la parodia de ese radicalismo anticlerical, una parodia tras la que se escondía parte del drama ideológico republicano: si se republicanizaba el régimen como deseaban los anticlericales revolucionarios y demagógicos, se optaba por una política sectaria que no dejaba espacio a opciones políticas tan diferentes como legítimas en democracia. El artículo 26, incluso disgustando al anticlericalismo más extremo, vino a demostrar que era muy difícil elaborar un marco constitucional sin escapar del discurso ideológico cultivado meses atrás, esto es, sin negar la existencia política, social y cultural de un amplio sector de la sociedad española y sin renunciar a una Constitución que consagrase en el plano jurídico la peligrosa demagogia revolucionaria. 